\title{
Counterregulatory hormonal responses to hypoglycaemia in Type 1 (insulin-dependent) diabetes: evidence for diminished hypothalamic-pituitary hormonal secretion
}

\author{
B. M. Frier ${ }^{1}$, B. M. Fisher ${ }^{1}$, C. E. Gray² and G. H. Beastall ${ }^{2}$ \\ ' Diabetic Department, Western Infirmary and Gartnavel General Hospital and ${ }^{2}$ Biochemistry Department, Royal Infirmary, Glasgow, UK
}

\begin{abstract}
Summary. Acute insulin-induced hypoglycaemia in humans provokes autonomic neural activation and counterregulatory hormonal secretion mediated in part via hypothalamic stimulation. Many patients with Type 1 (insulin-dependent) diabetes have acquired deficiencies of counterregulatory hormonal release following hypoglycaemia. To study the integrity of the hypothalamic-pituitary and the sympatho-adrenal systems, the responses of pituitary hormones, beta-endorphin, glucagon and adrenaline to acute insulin-induced hypoglycaemia $(0.2$ units $/ \mathrm{kg})$ were examined in 16 patients with Type 1 diabetes who did not have autonomic neuropathy. To examine the effect of duration of diabetes these patients were subdivided into two groups (Group 1: 8 patients $<5$ years duration; Group 2: 8 patients $>15$ years duration) and were compared with 8 normal volunteers (Group 3 ). The severity and time of onset of hypoglycaemia were similar in all 3 groups, but mean blood glucose recovery was slower in the diabetic groups $(p<0.01)$. The mean responses of glucagon, adrenaline, adrenocorticotrophic hormone, prolactin and be-
\end{abstract}

ta-endorphin were similar in all 3 groups, but the mean responses of growth hormone were lower in both diabetic groups than in the normal group $(p<0.05)$. The mean increments of glucagon and adrenaline in the diabetic groups were lower than the normal group, but these differences did not achieve significance; glucagon secretion was preserved in several diabetic patients irrespective of duration of disease. Various hormonal responses to hypoglycaemia were absent or diminished in individual diabetic patients, and multiple hormonal deficiencies could be implicated in delaying blood glucose recovery. The demonstration of subnormal secretion of adrenaline and pituitary hormones following hypoglycaemia in individual patients supports the concept that central (hypothalamic) activation of counterregulation may be diminished in Type 1 diabetes.

Key words: Hypoglycaemia, insulin, diabetes mellitus, hypothalamus, pituitary hormones, beta-endorphin, adrenaline.
Acute insulin-induced hypoglycaemia in man stimulates the release of several hormones, some of which contribute to glucose counterregulation. The integrated counterregulatory response in primates is thought to be initiated centrally within the hypothalamus [1], with simultaneous activation of the autonomic centres and the hypothalamic-pituitary system. The profound sympatho-adrenal response with secretion of catecholamines is accompanied by the release of prolactin, adrenocorticotrophic hormone (ACTH) and growth hormone from the anterior pituitary gland, and also of the opioid peptide, beta-endorphin [2], which shares a common precursor with ACTH [3]. Glucagon secretion following acute hypoglycaemia occurs independently of autonomic stimulation and hypothalamic control [4].

Deficiencies of various counterregulatory hormonal responses to acute hypoglycaemia occur in patients with Type 1 (insulin-dependent) diabetes, the dual fail- ure of glucagon and adrenaline secretion being implicated in the impairment of blood glucose recovery [5]. The secretion of adrenaline in response to hypoglycaemia appears to diminish with increasing duration of diabetes, and may be caused by autonomic neuropathy [6]. Because the sympatho-adrenal response depends upon activation of central autonomic centres, the concurrent secretion of pituitary hormones in response to acute hypoglycaemia provides an indicator of hypothalamic activation, irrespective of the minimal role which these pituitary hormones may have in rapid glucose counterregulation. To assess the functional integrity of the hypothalamic centre which activates counterregulation the secretory responses to acute hypoglycaemia of adrenaline, pituitary hormones and beta-endorphin were examined in patients with Type 1 diabetes of varying duration, who had no evidence of peripheral autonomic neuropathy. 
Table 1. Clinical characteristics of Type 1 diabetic patients with duration of diabetes less than 5 years (Group 1$)$ and greater than 15 years (Group 2)

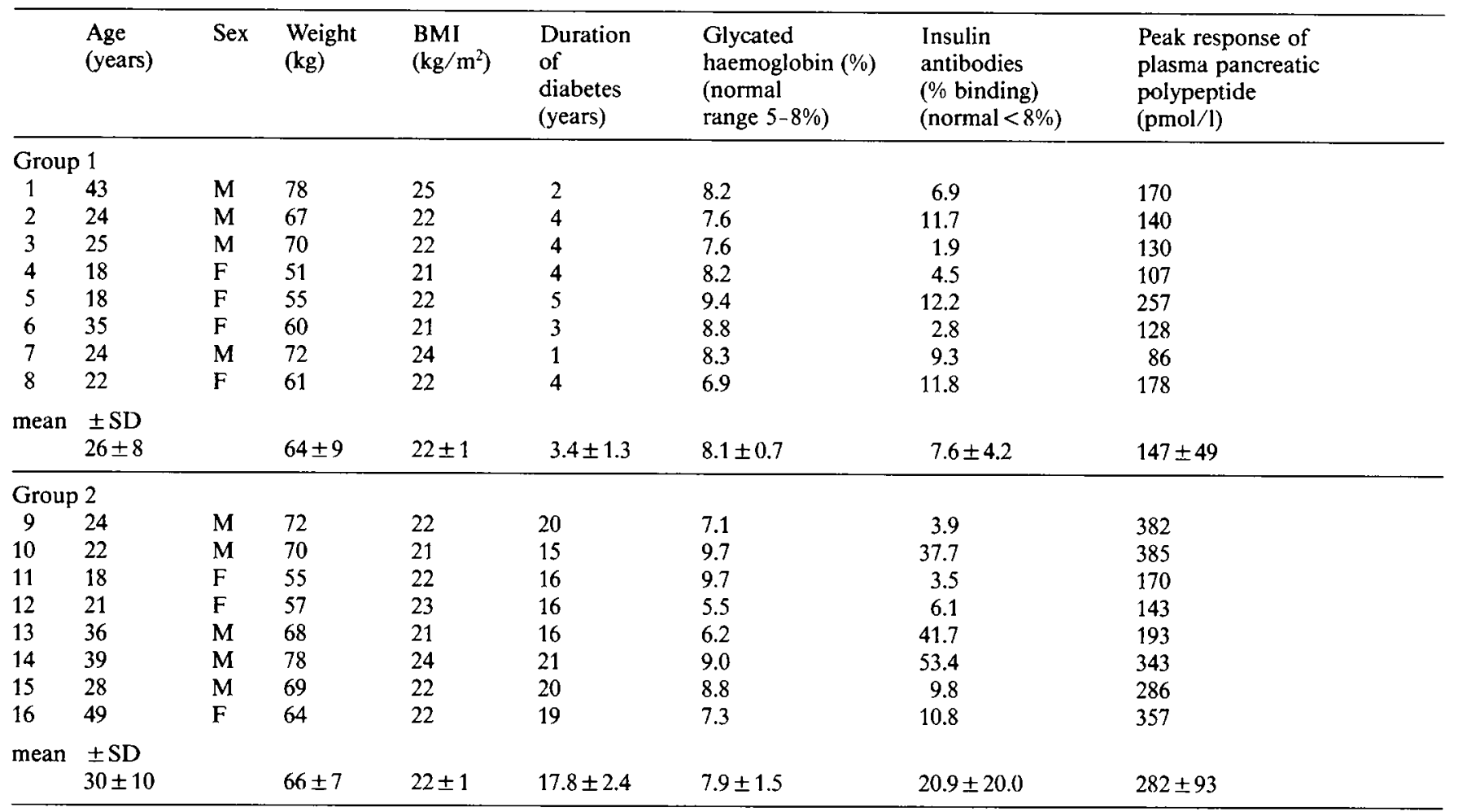

\section{Subjects and methods}

Permission for the study was granted by the local medical ethical advisory committee, and informed consent was obtained from all participants. Sixteen patients with Type 1 diabetes were recruited from the Diabetic Clinic, Western Infirmary/Gartnavel General Hospital, Glasgow and clinical characteristics are shown in Table 1. None of the subjects was taking any medication and all had a normal body mass index (BMI). The diabetic patients were subdivided into two groups depending on duration of diabetes:

Group 1: 8 patients (4 male, 4 female) with duration of diabetes from $1-5$ years, age range 18 to 43 years.

Group 2: 8 patients ( 5 male, 3 female) with duration of diabetes greater than 15 years (range 15-21 years), age range 18 to 49 years.

Group 3: 8 healthy, non-diabetic control subjects ( 6 male, 2 female), age range 21 to 45 years, who were recruited from hospital staff. Body weight (mean $\pm \mathrm{SD}$ ) was $68 \pm 8 \mathrm{~kg}$ with a BMI of $23 \pm 1$.

The diabetic patients all had good glycaemic control, with glycated haemoglobin values of less than $10 \%$, and the absence of residual endogenous secretion of insulin was determined by measurement of plasma C-peptide both fasting and in response to $1 \mathrm{mg}$ of intravenous glucagon [7]. None of the diabetic patients gave historical evidence of hypoglycaemic unawareness, nor had experienced recent symptoms or episodes of hypoglycaemia.

The diabetic patients were all screened for the presence of complications. Autonomic neural function was evaluated using a group of tests of cardiovascular reflexes [8] to ensure that patients with autonomic dysfunction were not included. This was verified by demonstrating a normal rise of plasma pancreatic polypeptide following hypoglycaemia [9] which was defined as a peak value greater than $40 \mathrm{pmol} / \mathrm{l}$ (Table 1). Mild background diabetic retinopathy (less than 3 microaneurysms/fundus) was observed in 3 patients by direct ophthalmoscopy and none of the diabetic patients had clinical evidence of peripheral neuropathy. None of the patients had an increased excretion of urinary albumin on testing with a simple latex agglutination test, Albuscreen (Cambridge Life Sciences, Cambridge, UK) [10].

\section{Protocol}

The diabetic patients were treated for one week with continuous subcutaneous insulin infusion (CSII) using a Betatron 1 pump (Eli Lilly \& Co Ltd, Basingstoke, UK) to optimize glycaemic control before the acute hypoglycaemic study was performed. Care was taken to avoid hypoglycaemia during this period and routine home blood glucose monitoring included nocturnal measurements. After an overnight fast, each subject was maintained supine, an indwelling teflon cannula was inserted into an antecubital vein and kept patent with $0.9 \%$ saline. The subcutaneous insulin infusion was stopped $15 \mathrm{~min}$ before basal sampling of venous blood. To ensure a rapid fall in blood glucose to below $2.0 \mathrm{mmol} / \mathrm{l}$, a large dose of short-acting, soluble insulin (Actrapid-MC, Novo Laboratories Ltd, Basingstoke, $\mathrm{UK} ; 0.2 \mathrm{U} / \mathrm{kg}$ body weight) was given as an i.v. bolus injection, and the time to the onset of the acute autonomic reaction $(R)$ to hypoglycaemia was recorded; in all subjects $R$ coincided with the nadir of blood glucose, and was manifested by an abrupt rise in heart rate and the onset of autonomic symptoms. Frequent monitoring of blood glucose was performed during the induction of hypoglycaemia using a Reflolux II glucometer (Boehringer Corporation (London) Ltd, Lewes, UK) to assist determination of the blood glucose nadir in each subject. Because of individual variation in the time of onset of $R$ after the administration of $i . v$. insulin, subsequent serial blood sampling was timed from $R$ until $R+180$ min. Plasma was separated immediately and stored at $-20^{\circ} \mathrm{C}$.

Blood glucose was measured using a hexokinase method with the Cobas Bio analyser (Roche Diagnostica, Basel, Switzerland). Glycated haemoglobin $\left(\mathrm{HbA}_{1}\right)$ was measured by gel-electrophoresis. Insulin antibodies were measured using a microenzyme-linked immunosorbent assay [11]. Plasma growth hormone was measured by a 
double antibody radioimmunoassay, standardised against the first international reference preparation of growth hormone (MRC 66/217) and plasma adrenaline by a radioenzymatic assay [12]. Plasma pancreatic polypeptide [13], ACTH [14], prolactin [15] and glucagon (C-terminal glucagon-like immunoreactivity) [16] were measured by radioimmunoassays and plasma beta-endorphin by a sensitive, disequilibrium radioimmunoassay standardised against synthetic human beta-endorphin following affinity gel extraction (Immuno Nuclear Corporation, Stillwater, Minn, USA). The crossreactivity with beta-lipotropin was less than $5 \%$.

Despite the long-established use of the insulin tolerance test in endocrinological investigation, a normal range of hormonal increments to acute insulin-induced hypoglycaemia has rarely been defined in published reports. To interpret the hormonal responses to hypoglycaemia of individual diabetic patients, the normal magnitude of hormonal increments was determined arbitrarily by the lowest maximal increment observed in the individual subjects of the normal group. A delayed blood glucose recovery from hypoglycaemia was defined as a blood glucose concentration of less than $2.0 \mathrm{mmol} / \mathrm{l}$ at $\mathrm{R}+120 \mathrm{~min}$. "Normal" responses to hypoglycaemia were defined for individual hormones: adrenaline as a peak concentration above $2.5 \mathrm{nmol} / \mathrm{l}$, prolactin as a peak concentration greater than $600 \mathrm{mU} / \mathrm{l}$, $\mathrm{ACTH}$ as a peak concentration greater than $30 \mathrm{mU} / \mathrm{l}$, and growth hormone as a peak concentration greater than $40 \mathrm{mU} / 1$, the latter being of similar magnitude to the growth hormone responses derived from insulin stress tests which used an insulin dose of $0.15 \mathrm{U} / \mathrm{kg}$ body weight [17].

\section{Statistical analysis}

Results are expressed as mean \pm SEM, and statistical differences were examined using analyses of variance, providing tests of significance between the three groups. Where significant differences in mean responses were found, these were examined further using Student's t-test for unpaired data. The times to onset of the acute hypoglycaemic reaction ( $R$ ) were compared using the Mann-Whitney $\mathrm{U}$ Test. Correlation coefficients were calculated using the method of provisional means.

\section{Results}

All subjects developed objective evidence of an acute hypoglycaemic reaction $(R)$ with an increase in heart rate, sweating and moderate neuroglycopenia. The latter was more pronounced and persisted for longer in four of the diabetic patients (No.'s 5, 11, 14, 16; see Table 1). None of the diabetic patients had overt hypoglycaemic unawareness during the study.

No significant differences were observed in the mean times from i.v. injection of insulin to the onset of the acute autonomic reaction between any of the three groups; 36 min for Group 1, 33 min for Group 2 and 30 min for Group 3.

\section{Glucose}

The mean blood glucose concentration (mean \pm SEM) fell rapidly in all groups to a similar nadir (Group 1: $0.9 \pm 0.2 \mathrm{mmol} / 1$; Group 2: $0.8 \pm 0.2 \mathrm{mmol} / 1$; Group 3: $1.0 \pm 0.1 \mathrm{mmol} / \mathrm{l}$ ) which coincided with the onset of the acute hypoglycaemic reaction $(R)$. The rate of fall of blood glucose did not differ between the three groups, but the mean blood glucose recovery from hy-

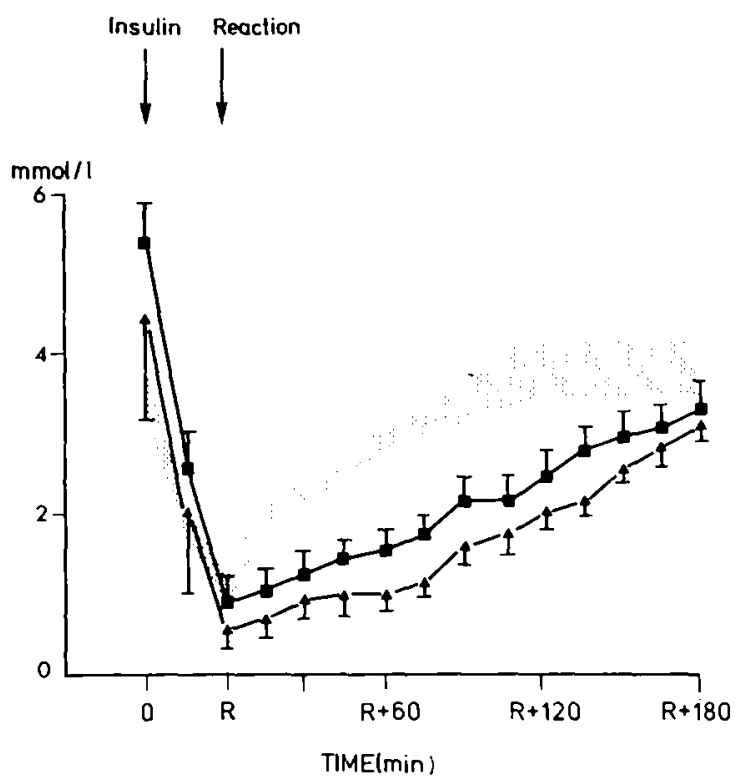

Fig. 1. Mean blood glucose changes during hypoglycaemia. Changes in mean blood glucose in response to insulin-induced hypoglycaemia in normal, non-diabetic subjects (hatched area, mean \pm SEM) and in diabetic patients, less than 5 years $(\square)$ and greater than 15 years ( $\mathbf{A}$ ) duration. Insulin was given at time 0 and $\mathrm{R}$ denotes acute autonomic reaction

poglycaemia was delayed in both diabetic groups compared to the normal group $(p<0.01$ at all times of measurement from $R+15 \mathrm{~min})$. No significant differences in blood glucose recovery were found between the two diabetic groups at all times of measurement (Fig.1). An impaired recovery of blood glucose was observed in one patient in Group 1, and in five patients in Group 2.

\section{Prolactin}

Plasma prolactin rose from a basal value of $257 \pm$ $39 \mathrm{mU} / 1$ (mean \pm SEM) to a maximum of $1176 \pm$ $131 \mathrm{mU} / 1$ at $\mathrm{R}+30 \mathrm{~min}$ in the normal group $(p<0.01$ compared to basal). Similar mean responses were found in both diabetic groups but the peak responses were temporally delayed, particularly in Group 1 (Fig.2). Although the maximal value was lowest in Group 2, (Type 1 diabetes $>15$ years duration) this difference was not statistically significant from the other groups. The individual responses of prolactin rose to a value grater than $600 \mathrm{mU} / 1$ in all normal subjects in Group 3, but the increments were reduced or absent in 3 diabetic patients in Group 1 and in 4 in Group 2 (Fig. 3).

\section{Adrenocorticotrophic hormone}

In the normal subjects (Group 3), the mean plasma $\mathrm{ACTH}$ rose to $35 \pm 8 \mathrm{mU} / 1$ at $\mathrm{R}+30 \mathrm{~min}$ in response to hypoglycaemia $(p<0.01$ compared to basal). The peak values of plasma ACTH in the two diabetic 

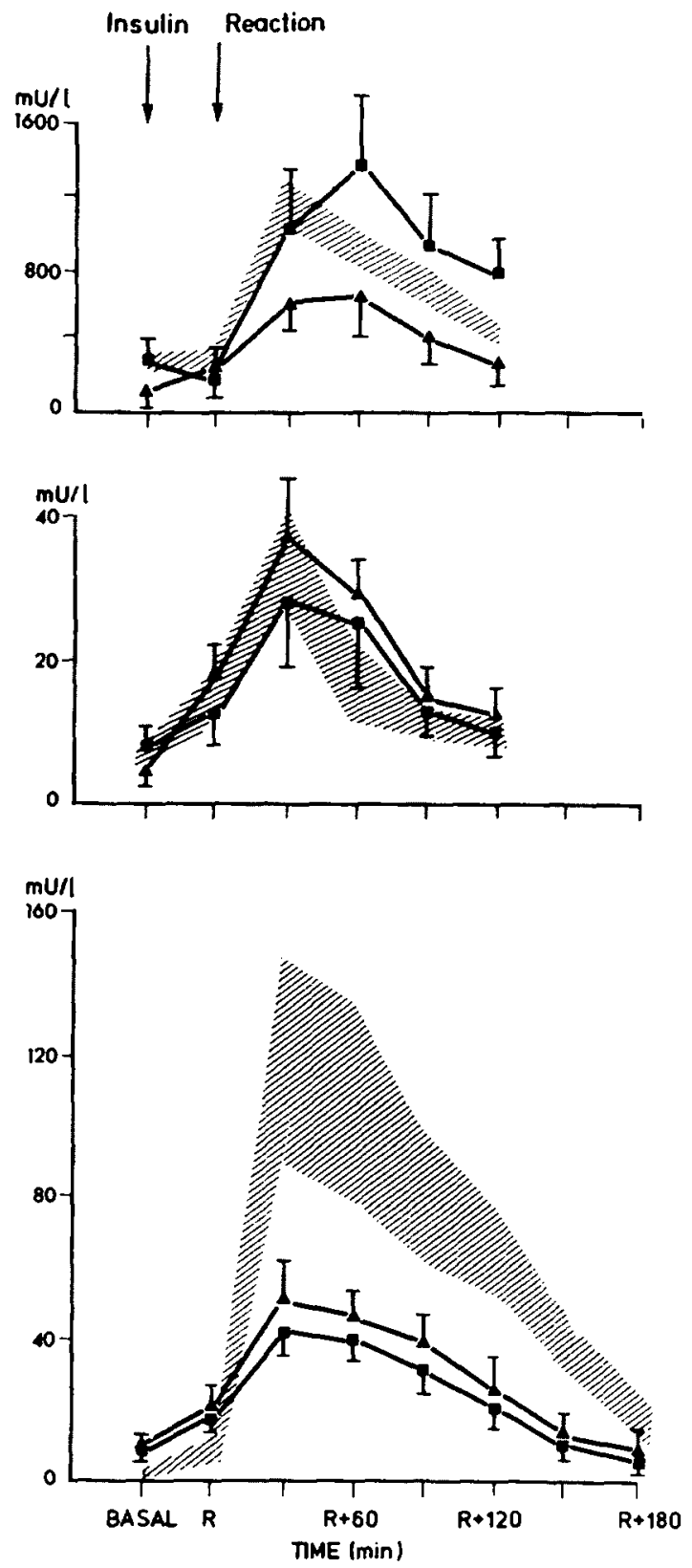

Fig. 2. Changes in mean plasma concentrations of prolactin (upper panel), ACTH (middle panel) and growth hormone (lower panel) in response to acute hypoglycaemia in normal subjects (hatched area $\mathbb{R}$, mean $\pm \mathrm{SEM}$ ) and in diabetic patients less than 5 years $(\boldsymbol{D})$ and greater than 15 years $(\Delta)$ duration. ( $R$ denotes acute autonomic reaction)

groups did not differ significantly from Group 3, rising to $31 \pm 8 \mathrm{mU} / 1$ in Group 1 and to $38 \pm 8 \mathrm{mU} / 1$ in Group 2 (Fig. 2). An ACTH increment (peak > $30 \mathrm{mU} / \mathrm{l}$ ) occurred in all of the normal subjects during hypoglycaemia, but a diminished response was observed in three diabetic subjects in Group 1 and in three in Group 2 (Fig. 3).

\section{Growth hormone}

In the normal group (Group 3) the mean concentration of plasma growth hormone $(\mathrm{GH})$ rose to $125 \pm$
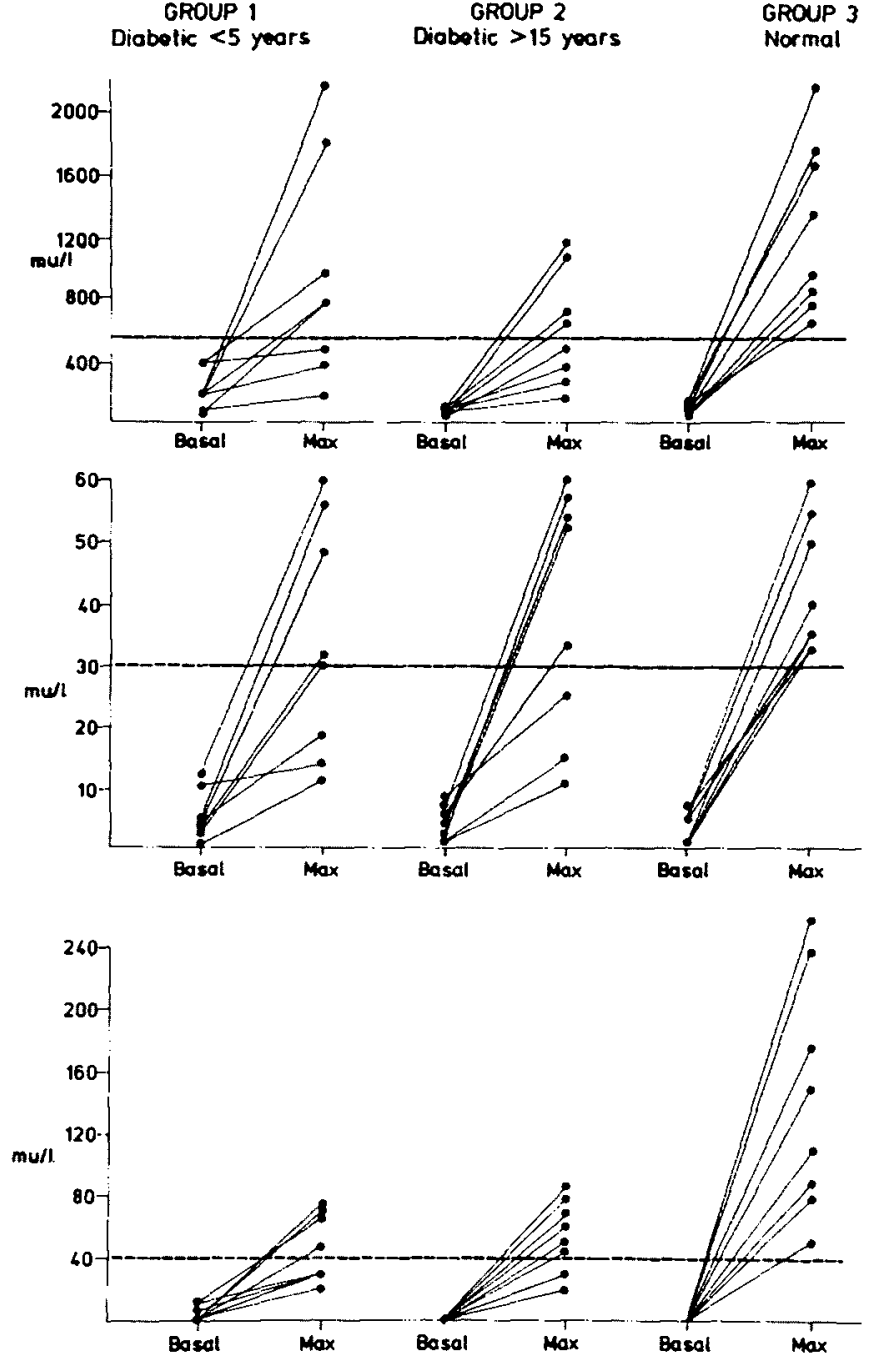

Fig. 3. Maximal increments following hypoglycaemia of plasma prolactin (upper panel), ACTH (middle panel) and growth hormone (lower panel) in individual subjects from diabetic and normal groups. The broken horizontal line (-..-) indicates the defined lower limit of a normal response to hypoglycaemia for each hormone

$40 \mathrm{mU} / 1$ at $\mathrm{R}+30 \mathrm{~min}(p<0.01$ compared to basal) (Fig. 2). The increase of plasma $\mathrm{GH}$ in both diabetic groups was significantly lower with peak values of $41 \pm 7 \mathrm{mU} / 1$ in Group 1 , and $57 \pm 7 \mathrm{mU} / 1$ in Group 2 at $\mathrm{R}+30 \mathrm{~min}(p<0.05$ compared to Group 3$)$. A normal $\mathrm{GH}$ response to hypoglycaemia (peak $>40 \mathrm{mU} / \mathrm{l}$ ) occurred in all of the non-diabetic subjects, but the GH response was generally lower in all the diabetic subjects and was subnormal in 4 patients of Group 1 and in 2 of Group 2 (Fig. 3).

\section{Beta-Endorphin}

In the normal group (Group 3) a rise in plasma betaendorphin occurred in response to hypoglycaemia, from a basal value of $5.0 \pm 1.2 \mathrm{pmol} / 1$ to $7.6 \pm$ $1.0 \mathrm{pmol} / \mathrm{l}$ at $\mathrm{R}$, and to $19.5 \pm 3.8 \mathrm{pmol} / 1$ at $\mathrm{R}+30 \mathrm{~min}$ (Fig.4). In the diabetic groups the mean concentrations 


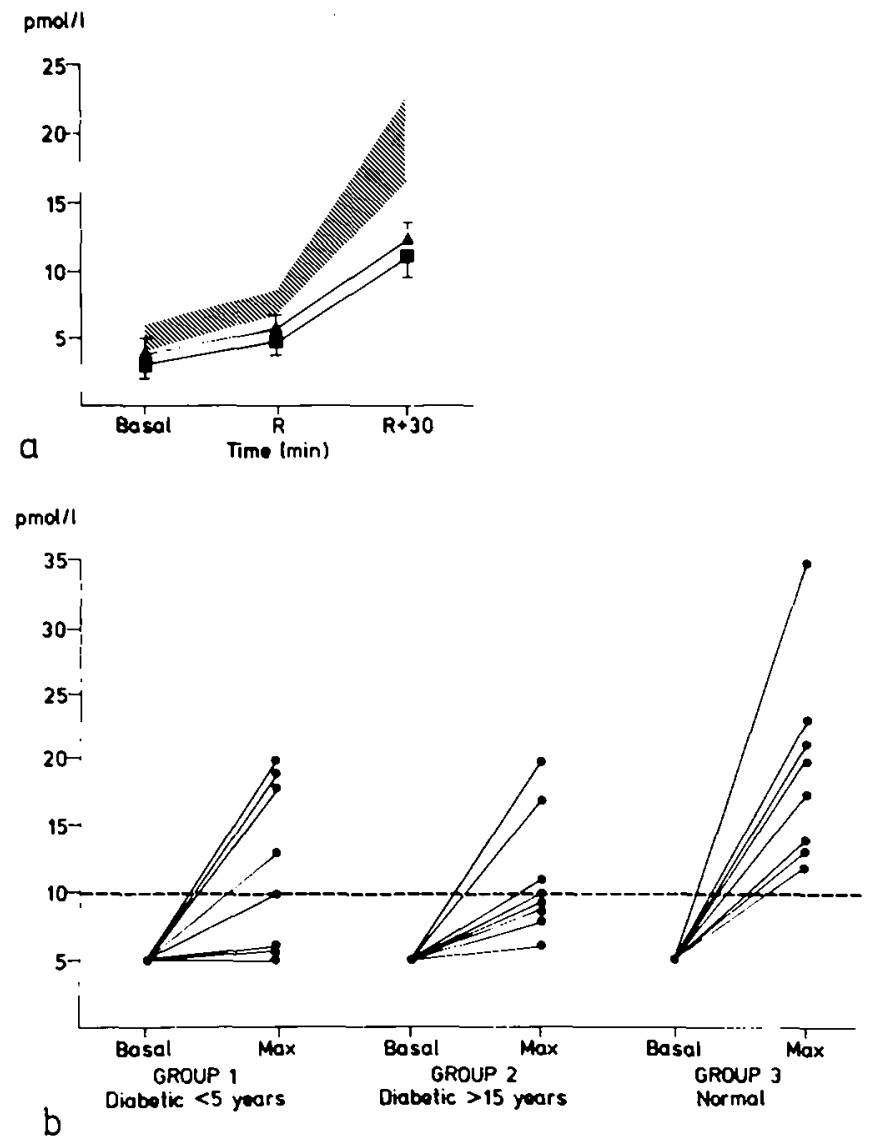

Fig. $4 \mathrm{a}$ and $\mathrm{b}$. Changes in plasma beta-endorphin following acute hypoglycaemia in normal and diabetic groups a Mean ( \pm SEM) plasma concentrations in response to hypoglycaemia in normal subjects (hatched area $\square$ ) and in diabetic patients less than 5 years ( and greater than 15 years $(\Delta)$ duration. b Maximal increments following hypoglycaemia in individual subjects. The broken horizontal line (-..-) indicates the lower limit of a normal response

were lower at $\mathrm{R}+30 \mathrm{~min}$ with values of $12.1 \pm$ $2.4 \mathrm{pmol} / 1$ in Group 1 and $11.4 \pm 1.7 \mathrm{pmol} / 1$ in Group 2, but these differences did not achieve statistical significance when compared with Group 3. The lower limit of a normal individual response to hypoglycaemia was defined arbitrarily as a peak value above $10 \mathrm{pmol} / 1$. Using this value, the beta-endorphin response was reduced in 4 patients in Group 1 and in 5 in Group 2 (Fig.4).

\section{Adrenaline}

Basal concentrations of plasma adrenaline were similar in all three groups. The peak response of plasma adrenaline occurred at $\mathrm{R}+30 \mathrm{~min}$ in all groups with the highest mean value occurring in the normal group (Group 3) of $5.6 \pm 1.0 \mathrm{nmol} / 1$ ( $p<0.02$ compared to basal). The peak responses in both diabetic groups were lower at $4.3 \pm 0.8 \mathrm{nmol} / 1$ in Group 1 and $3.7 \pm$ $0.8 \mathrm{nmol} / 1$ in Group 2, but these values were not significantly different from the normal response (Fig. 5). Using the arbitrarily defined "normal" response for
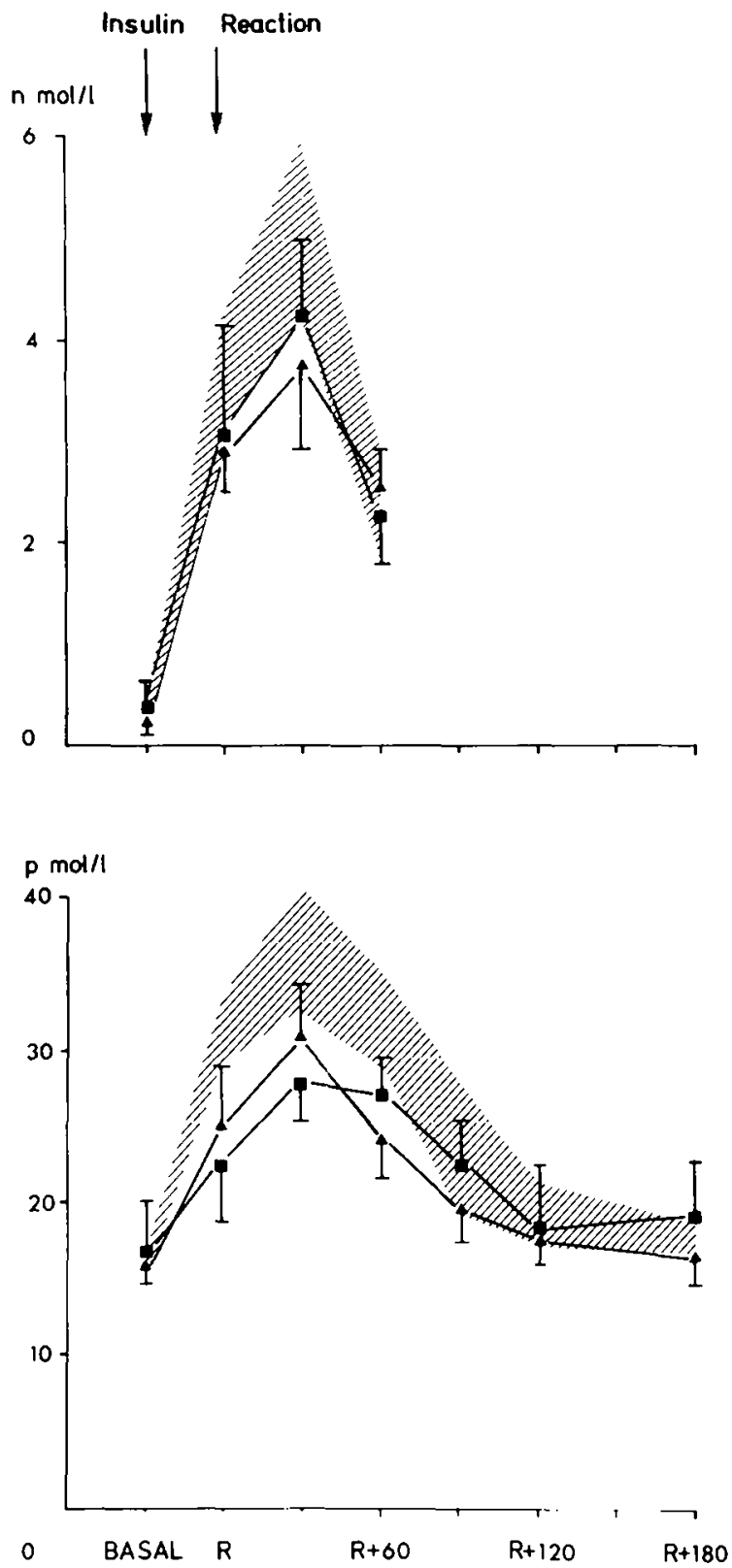

Fig. 5. Changes in mean plasma adrenaline (upper panel) and glucagon (lower panel) concentrations in response to acute hypoglycaemia in normal subjects (hatched area $\square$, mean $\pm S E M$ ) and in diabetic patients less than 5 years $(\boldsymbol{\square})$ and greater than 15 years $(\boldsymbol{\Delta})$ duration

adrenaline, two diabetic patients were subnormal in Group 1, and 3 in Group 2 (Fig.6). No significant correlation was found between the maximal adrenaline concentration and the peak values of prolactin, ACTH, $\mathrm{GH}$ or beta-endorphin in any of the groups.

\section{Glucagon}

The mean responses of plasma glucagon to acute hypoglycaemia are shown in Figure 5. The peak response occurred at $R+30 \mathrm{~min}$ in all three groups and although higher in the normal group the differences with the diabetic groups did not achieve statistical signifi- 


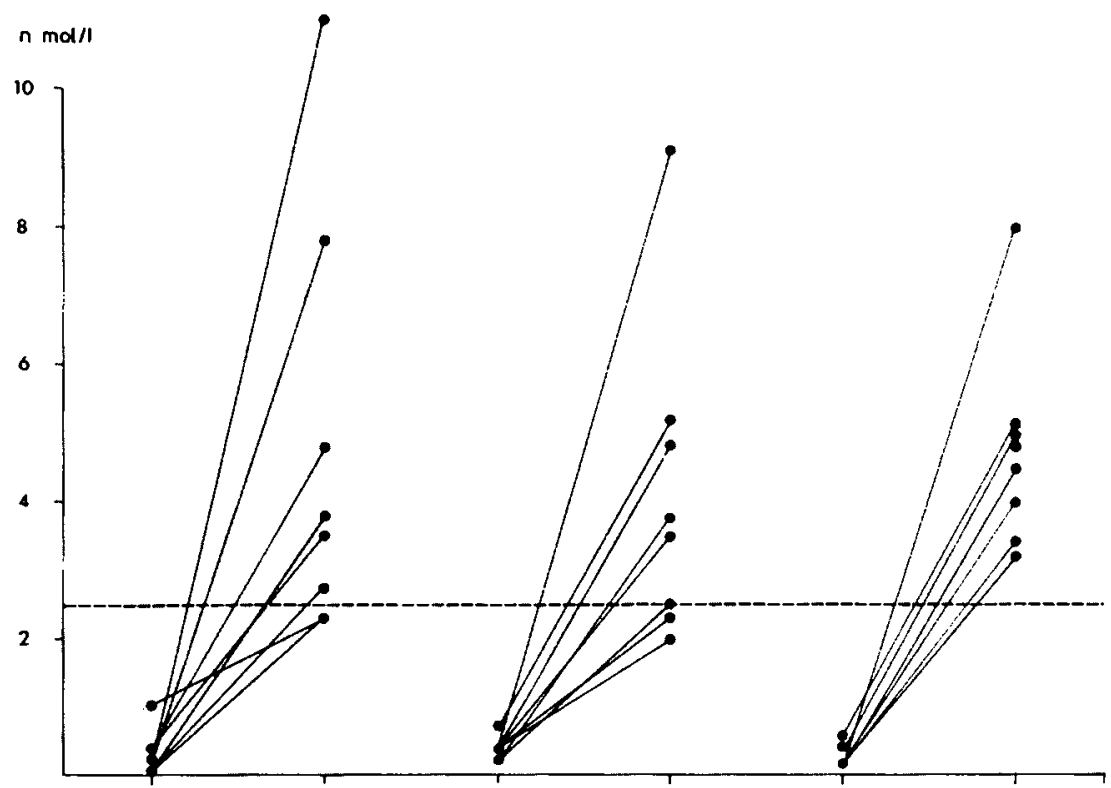

$\rho \mathrm{mol} / \mathrm{l}$

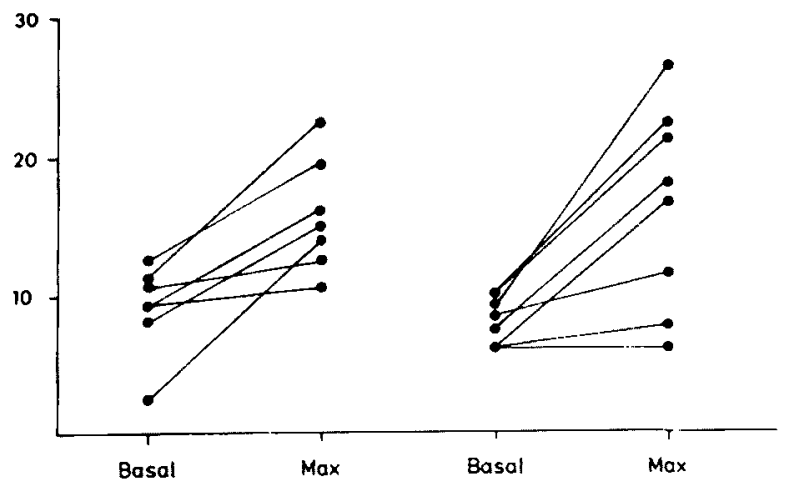

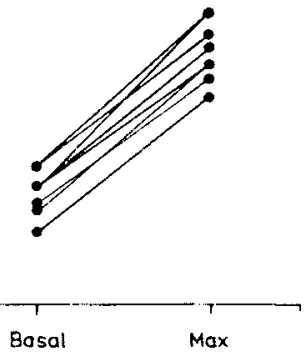

Fig. 6. Maximal increments following hypoglycaemia of plasma adrenaline (upper panel) and glucagon (lower pancl) in individual subjects from diabetic and normal groups. The broken horizontal line (-.--) indicates the defined lower limit of a "normal" response to hypoglycaemia cance. The maximal increments of individual subjects are shown in Figure 6. The pattern of glucagon response was examined in preference to the absolute values, and was absent or subnormal in 2 diabetic patients in Group 1 and in 3 in Group 2, while remaining intact in all other diabetic patients irrespective of the duration of diabetes.

The frequency of subnormal or absent responses to hypoglycaemia of individual hormones and beta-endorphin in the diabetic patients is shown in Table 2. The diabetic patients with delayed recovery of blood glucose (No.'s 3, 9-12, 14) appeared to have multiple deficiencies of hormonal secretion in response to hypoglycaemia in comparison with other patients.

\section{Discussion}

Activation of the sympatho-adrenal system is a major feature of the response to acute hypoglycaemia in hu- mans [18]. This is thought to be initiated within the autonomic centres in the hypothalamus [1]; the resulting autonomic neural stimulation and release of catecholamines provoke many of the classical symptoms of hypoglycaemia. Glucose counterregulation is mediated principally by glucagon and adrenaline [5], the secretion of both of which can become deficient in patients with Type 1 diabetes and may impair blood glucose recovery $[5,19]$. The pituitary hormones appear to have a subservient role in short-term glucose counterregulation, but the magnitude of hormonal secretion by the pituitary gland following hypoglycaemia provides an index of preceding hypothalamic activation. In the absence of peripheral autonomic neuropathy, a blunted hypothalamic response to hypoglycaemia might underlie the reduced release of catecholamines observed in patients with Type 1 diabetes of long duration [6]. Mean responses can mask abnormal hormonal secretion in individual subjects, so the increments of each hormone from basal to peak values were examined in 
Table 2. Impaired blood glucose recovery following hypoglycaemia and subnormal hormonal responses $(\phi)$ in individual Type 1 diabetic patients. "Normal" responses are left blank. "Patients with significant titres of insulin antibodies

\begin{tabular}{|c|c|c|c|c|c|c|c|}
\hline & $\begin{array}{l}\text { Blood } \\
\text { glucose } \\
\text { recovery }\end{array}$ & Glucagon & Adrenaline & ACTH & GH & Prolactin & Beta-endorphin \\
\hline \multicolumn{8}{|l|}{ Group 1} \\
\hline 1 & & & & & t & & \\
\hline $2^{\mathrm{a}}$ & & & & & & 1 & \\
\hline 3 & 1 & 1 & & $t$ & $\downarrow$ & $i$ & $t$ \\
\hline 4 & & & & & & & t \\
\hline $5^{\mathrm{a}}$ & & & $\downarrow$ & & p & & \\
\hline $\begin{array}{l}6 \\
7\end{array}$ & & & $\downarrow$ & t & & & 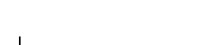 \\
\hline $\begin{array}{l}7 \\
8^{\mathrm{a}}\end{array}$ & & 1 & & $t$ & 1 & 1 & $i$ \\
\hline Subnormal & 1 & 2 & 2 & 3 & 4 & 3 & 4 \\
\hline \multicolumn{8}{|l|}{ Group 2} \\
\hline 9 & 1 & 1 & & & & 1 & $t$ \\
\hline $10^{3}$ & $i$ & 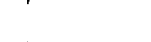 & $t$ & & 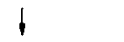 & $i$ & i \\
\hline 11 & $i$ & 1 & & t & & $i$ & \\
\hline 12 & $i$ & $i$ & 1 & i & & $i$ & 1 \\
\hline $13^{a}$ & & & & & & & $i$ \\
\hline $14^{a}$ & 1 & & $t$ & 1 & $\downarrow$ & & i \\
\hline 15 & & & & & & & \\
\hline \multicolumn{8}{|l|}{16} \\
\hline Subnormal & 5 & 3 & 3 & 3 & 2 & 4 & 5 \\
\hline Total $(\%)$ & $6(38 \%)$ & $5(31 \%)$ & $5(31 \%)$ & $6(38 \%)$ & $6(38 \%)$ & $7(44 \%)$ & $9(56 \%)$ \\
\hline
\end{tabular}

the present investigation to identify subnormal or absent responses to hypoglycaemia in individual diabetic patients.

In the present study the recovery of blood glucose in both diabetic groups was significantly delayed compared with the normal group. Attenuated recovery of blood glucose after hypoglycaemia in individual diabetic patients was more common in those with longstanding diabetes and presumably was related to diminished secretion of glucagon and/or adrenaline, although these patients also appeared to have a greater frequency of hormonal deficiencies to hypoglycaemic stress. Neither the delayed recovery of blood glucose nor the subnormal adrenaline responses in individual diabetic patients could be attributed to autonomic neuropathy, which was excluded by formal testing of cardiovascular reflexes and by demonstrating a normal rise of plasma pancreatic polypeptide following hypoglycaemia in all subjects [9]. No correlation was observed between the maximum adrenaline and pancreatic polypeptide responses in both diabetic groups, which precluded the possibility that patients with subnormal adrenaline secretion had subclinical autonomic neuropathy [20]. Although raised titres of insulin antibodies in diabetic patients may cause protracted hypoglycaemia by altering the pharmacokinetics of insulin $[21,22]$, in the present study the titre of insulin antibodies was markedly elevated in only three diabetic patients (No.'s 10, 13, 14), all of whom had diabetes of longer duration. Two of these individuals had delayed blood glucose recovery, but also had multiple subnormal responses of counterregulatory hormones.

Glucagon secretion following hypoglycaemia occurs independently of hypothalamic and autonomic neural stimulation but pancreatic alpha cell sensitivity to glucopenia appears to decline with duration of diabetes [4-6]. Most individual diabetic patients in the present study, including many of long duration, retained the capacity to secrete glucagon in response to a profound hypoglycaemic stimulus, which contradicts the view that total failure of glucagon secretion to this stress is inevitable within a few years of the development of diabetes $[5,6]$. Stimulation of a secretory response from diabetic pancreatic alpha cells may depend upon the degree of hypoglycaemia achieved or the method of induction with a large bolus dose of intravenous insulin, in comparison with previous studies in which insulin was administered in lower dosage by a slower intravenous infusion. The present study indicates that a secretory response of glucagon will occur in many patients with diabetes of long duration if the hypoglycaemic stimulus is of sufficient severity.

The mean responses of growth hormone were lower in both groups of diabetic patients following hypoglycaemia, and may be of functional importance to impaired glucose counterregulation in prolonged hypoglycaemia [23]. No significant reductions were observed however in the mean responses of prolactin and $\mathrm{ACTH}$, and the reason for this dissociation with growth hormone is not clear. It may represent develop- 
ment of selective hypothalamic insensitivity for pituitary hormonal secretion, as the secretion of growth hormone and adrenaline in Type 1 diabetic patients was diminished following hypoglycaemia but was normal in response to exercise [24], indicating that the magnitude of hormonal secretion is stimulus-dependent. However, diminished responses to hypoglycaemia of growth hormone [24-26] and cortisol [27, 28] have been described previously in patients with Type 1 diabetes, and another study demonstrated plasma increments of growth hormone, cortisol and adrenaline which were inappropriately low for the prevailing degree of hypoglycaemia [21]. A few diabetic patients with recurrent clinical hypoglycaemia and impaired blood glucose recovery have been described who have multiple deficiencies of counterregulatory hormones, including growth hormone and $\mathrm{ACTH}$, in response to hypoglycaemia $[29,30]$.

The precise functional importance of pituitary hormonal deficiencies to glucose counterregulation is unclear, but the demonstration of single or multiple subnormal responses in individual diabetic patients suggests some form of hypothalamic dysfunction, without the development of overt pituitary or adrenal failure. Alternatively, the blood glucose concentration at which hypothalamic-pituitary secretion is stimulated may be lower than normal in these individuals. The glycaemic threshold for the release of cortisol is lower than that for growth hormone or adrenaline [31], which implies that a lower blood glucose is necessary to stimulate ACTH release than the other hormones secreted via hypothalamic-pituitary activation. In the present study the degree of hypoglycaemia achieved was of similar severity in the diabetic patients and the normal subjects, so the subnormal ACTH secretion observed in 6 diabetic patients was unlikely to be related to the absolute blood glucose concentration. Furthermore, the administration of a large dose of insulin ensured a rapid fall in blood glucose which remained low for a longer time in the diabetic patients; this protracted stimulus should augment rather than diminish counterregulatory hormonal secretion. Reduced central activation of the hypothalamus following hypoglycaemia would explain the subnormal pituitary hormonal responses of the individual diabetic patients in the present study.

Beta-endorphin is present in high concentration in the hypothalamus, is implicated in the regulation of hypothalamic-pituitary responses to stress [32], and in humans is released in response to hypoglycaemia from the anterior pituitary gland [2]. The counterregulatory role of beta-endorphin following hypoglycaemia is unknown in normal humans; its release in this situation has not been reported previously in diabetic patients. The content of beta-endorphin in the hypothalamus and anterior pituitary gland is reduced in insulin-dependent diabetic rats [33]. Subnormal responses of beta-endorphin to hypoglycaemia in individual diabetic patients in the present study suggests a possible reduc- tion in hypothalamic-pituitary beta-endorphin in human Type 1 diabetes, and is consistent with the concept of underlying hypothalamic dysfunction or reduced activation in some patients.

The quality of preceding glycaemic control may influence the threshold at which the hypothalamus responds to a hypoglycaemic stimulus [34]. Intensive insulin therapy for several months has been shown to influence hormonal counterregulatory responses to hypoglycaemia in diabetic patients, producing a quantitative reduction in the responses of growth hormone, cortisol and adrenaline [35]. Similarly the glycaemic threshold for the secretion of adrenaline was lowered in Type 1 diabetic patients by preceding optimal glycaemic control [36], and the perception of hypoglycaemic symptoms was decreased [37]. All, of our patients had good glycaemic control as measured by glycated haemoglobin, and this may have influenced the threshold of the counterregulatory hormonal responses to hypoglycaemia. Similarly, the maintenance of normoglycaemia using CSII, albeit for only a few days, may have reduced the magnitude of the hypothalamic-pituitary response to hypoglycaemia. The rapidity with which the central nervous system can adapt to prevailing glycaemia is unknown but an apparent hypothalamic insensitivity to hypoglycaemia might result from transient modification of glucose receptor function within the brain or of glucose transport across the blood-brain barrier [38]. Such a phenomenon might underlie the variability of counterregulatory hormonal responses to hypoglycaemia in individual patients with Type 1 diabetes.

Acknowledgements. Dr. B. M. Fisher was in receipt of a research fellowship from Eli Lilly; an equipment grant was received from Nordisk-UK. We are grateful to Ms. Mackay for secretarial assistance, to Dr. G.C. Inglis for assay of adrenaline, to Prof. K.D. Buchanan for assay of pancreatic polypeptide and glucagon and to the staff of the Department of Pathological Biochemistry, Gartnavel General Hospital, Glasgow for expert technical assistance. We also acknowledge the expertise of Dr. G. Gettinby who provided advice and assistance with statistical procedures.

\section{References}

1. Benzo CA (1983) The hypothalamus and blood glucose regulation. Life Sci 32: 2509-2515

2. Nakao K, Nakai $Y$, Jingami H, Oki S, Fukata J, Imura H (1979) Substantial rise of plasma $\beta$-endorphin levels after insulin-induced hypoglycemia in human subjects. J Clin Endocrinol Metab 49: 838-841

3. Guillemin R, Vargo T, Rossier J, Minick S, Ling N, Rivier C, Vale $\mathrm{W}$, Bloom $\mathrm{F}$ (1977) $\beta$-endorphin and adrenocorticotropin are secreted concomitantly by the pituitary gland. Science 197: 1367-1369

4. Frier BM (1986) Hypoglycaemia and diabetes. Diab Med 3: 513-525

5. Cryer PE, Gerich JE (1985) Glucose counterregulation, hypoglycemia, and intensive insulin therapy in diabetes mellitus. $\mathrm{N}$ Engl J Med 313: 232-241

6. Bolli G, De Feo P, Compagnucci P, Catechini MG, Angeletti G, Santeusanio F, Brunetti P, Gerich JE (1983) Abnormal glucose 
counterregulation in insulin-dependent diabetes mellitus. Interaction of anti-insulin antibodies and impaired glucagon and epinephrine secretion. Diabetes 32: 131-141

7. Faber OK, Binder C (1977) C-peptide response to glucagon. A test for the residual $\beta$-cell function in diabetes mellitus. Diabetes 26: $605-610$

8. Hilsted J (1984) Testing for autonomic neuropathy. Ann Clin Res 16: $128-135$

9. Krarup T, Schwartz TW, Hilsted J, Madsbad S, Verlaege O, Sestoft L (1979) Impaired response of pancreatic polypeptide to hypoglycaemia: an early sign of autonomic neuropathy in diabetes. Br Med J 2: 1544-1546

10. Spooner RJ, Weir RJ, Frier BM (1987) Detection of microalbuminuria in diabetic patients using a simple latex agglutination test. Clin Chim Acta 166: 247-253

11. Wilkin T, Nicholson S, Casey C (1985) A micro enzyme-linked immunosorbent assay for insulin antibodies in serum. J Immunol Methods 76: 185-194

12. Ball SG, Tree M, Morton JJ, Inglis GC, Fraser R (1981) Circulating dopamine: its effect on the plasma concentration of catecholamines, renin, angiotensin, aldosterone and vasopressin in the conscious dog. Clin Sci 61: 417-422

13. Bloom SR, Long RG (1982) Radioimmunoassay of gut regulatory peptides. Saunders, London, pp 51-153

14. Nicholson WE, Davis DR, Sherrell BJ, Orth DN (1984) Rapid radioimmunoassay for corticotropin in unextracted human plasma. Clin Chem 30: 250-265

15. Cowden EA, Ratcliffe WA, Beastall GH, Ratcliffe JG (1979) Laboratory assessment of prolactin status. Ann Clin Biochem 16: 113-121

16. Stout RW, Henry RW, Buchanan KD (1976) Triglyceride metabolism in acute starvation: the role of secretion and glucagon. Eur J Clin Invest 6: 179-185

17. Hall R, Anderson J, Smart GA, Besser M (1980) Fundamentals of clinical endocrinology, 3rd edn. Pitman Medical, Tunbridge Wells, pp 739-741

18. Cannon WB, Mclver MA, Bliss SW (1924) Studies on the conditions of activity in endocrine glands. XIII. A sympathetic and adrenal mechanism for mobilizing sugar in hypoglycaemia. Am J Physiol 69: 46-66

19. White NH, Skor DA, Cryer PE, Levandoski LA, Bier DM, Santiago JV (1983) Identification of type 1 diabetic patients at increased risk for hypoglycemia during intensive therapy. $\mathbf{N}$ Engl $\mathbf{J}$ Med 308: 485-491

20. Kennedy FP, Go VLW, Cryer PE, Bolli GB, Gerich JE (1988) Subnormal pancreatic polypeptide and epinephrine responses to insulin-induced hypoglycemia identify patients with insulin-dependent diabetes mellitus predisposed to develop overt autonomic neuropathy. Ann Intern Med 108: 54-58

21. Bolli G, Dimitriadis GD, Pehling GB, Baker BA, Haymond MW, Cryer PE, Gerich JE (1984) Abnormal glucose counterregulation after subcutaneous insulin in insulin-dependent diabetes. N Engl J Med 310: 1706-1711

22. Madsbad S, Hilsted J, Krarup T, Sestoft L, Christensen NJ, Tronier $B(1985)$ The importance of plasma free insulin and counterregulatory hormones for the recovery of blood glucose following hypoglycaemia in Type 1 diabetics. Acta Endocrinol 108: 224-230

23. Bolli GB, Gottesman IS, Cryer PE, Gerich JE (1984) Glucose counterregulation during prolonged hypoglycemia in normal humans. Am J Physiol 247: E206-E214
24. Hirsch BR, Shamoon H (1987) Defective epinephrine and growth hormone responses in Type I diabetes are stimulus specific. Diabetes $36: 20-26$

25. Molnar GD, Fatourechi V, Ackerman E, Taylor WF, Rosevear JW, Gatewood LC, Service FJ, Moxness KE (1971) Studies of inadvertent hypoglycemic episodes during continuous blood glucose analysis. J Clin Endocrinol Metab 32: 426-437

26. Polonsky K, Bergenstal R, Pons G, Schneider M, Jaspan J, Rubenstein A (1982) Relation of counterregulatory responses to hypoglycemia in Type I diabetes. N Engl J Med 307: 1106-1112

27. Serio M, Tarquini B, Contini P, Bucalossi A, Toccafondi R (1968) Plasma cortisol response to insulin and circadian rhythm in diabetic subjects. Diabetes 17: 124-126

28. Campbell LV, Kraegen EW, Meler H, Lazarus L (1979) Hormonal responses to insulin infusion in diabetes mellitus. Diabetologia 16: $359-364$

29. Boden G, Richard GA, Hoeldtke RD, Rezvani I, Owen OE (1981) Severe insulin-induced hypoglycemia associated with deficiencies in the release of counterregulatory hormones. $\mathrm{N}$ Engl $\mathbf{J}$ Med 305: 1200-1205

30. Ohwovoriole AE, Nairn IM, Bevan J, Baird JD (1982) Impaired ACTH and glucagon response to hypoglycaemia in an insulintreated diabetic. Postgrad Med J 58: 778-780

31. Schwartz NS, Clutter WE, Shah SD, Cryer PE (1987) Glycemic thresholds for activation of glucose counterregulatory systems are higher than the threshold for symptoms. J Clin Invest 79: $777-781$

32. Akil H, Watson SJ, Young E, Lewis ME, Khachaturian H, Walker JM (1984) Endogenous opioids: biology and function. Ann Rev Neurosci 7: 223-255

33. Forman LJ, Marquis DE, Stevens R, Adler R, Vasilenko P (1985) Diabetes induced by streptozocin results in a decrease in immunoreactive beta-endorphin levels in the pituitary and hypothalamus of female rats. Diabetes 34: 1104-1107

34. Cryer $P$ (1985) Does central nervous system adaptation to antecedent glycemia occur in patients with insulin-dependent diabetes mellitus? Ann Intern Med 103: 284-286

35. Simonson DC, Tamborlane WV, De Fronzo RA, Sherwin RS (1985) Intensive insulin therapy reduces counterregulatory hormone responses to hypoglycemia in patients with type 1 diabetes. Ann Intern Med 103: 184-190

36. Amiel SA, Tamborlane WV, Simonson DC, Sherwin RS (1987) Defective glucose counterregulation after strict glycemic control of insulin-dependent diabetes mellitus. $N$ Engl J Med 316: 1376-1383

37. Lager I, Attrall S, Blohme G, Smith U (1986) Altered recognition of hypoglycaemic symptoms in Type 1 diabetes during intensified control with continuous subcutaneous insulin infusion. Diab Med 3: 322-325

38. Gjedde A, Crone C (1981) Blood-brain glucose transfer. Regression in chronic hyperglycaemia. Science $214: 456-457$

Received: 25 January 1988

and in revised form: 10 May 1988

Dr. B. M. Frier

Diabetic Department

Royal Infirmary

Edinburgh EH3 9YW

UK 